\title{
The Ohio-Mississippi Floods of 1937
}

\section{By R. W. Davenport, U.S. Geological Survey}

SOME of the recent floods in the United States have indicated that, in any appraisal of the potentialities of a river system for producing floods, more significance than has perhaps been customary should be attached to the magnitude settlement of the region by white men, thus making a skeleton record going back one to three hundred years, varying with the time of such settlement. The available records may be sufficient to show with considerable reliability the char-

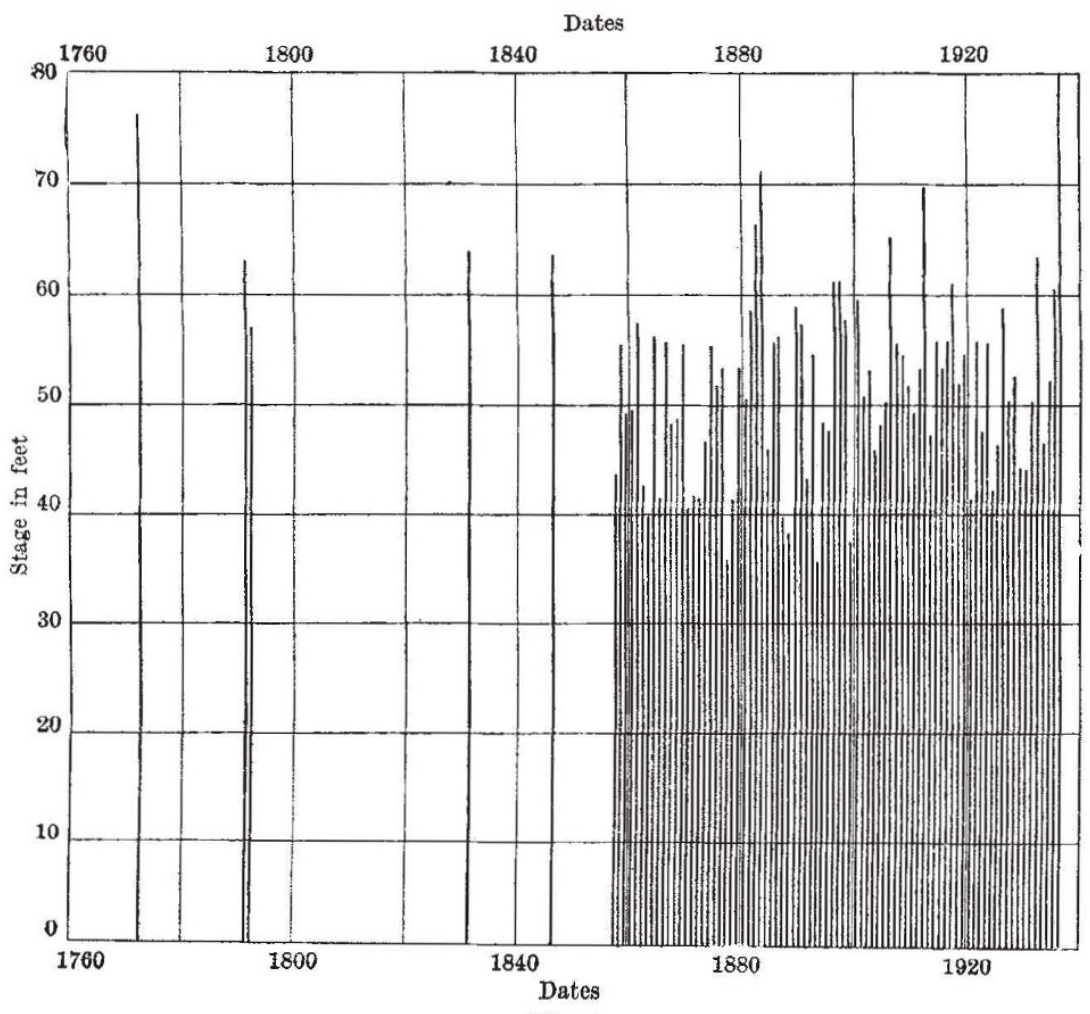

Fig. 1.

Maximum anndal flood stageis, Ohio River, Cincinnati, OHio, 1858-1937. (CHRONOLOGICAL ARRANGEMENT).

of the great floods of the past, as disclosed by Nature's records of them. A conspicuous part of the work of rivers in the processes of dynamic geology is associated with the occurrence of major floods, and significant information with respect to such floods may be appropriately and reliably interpreted from the flood plains, terraces, earlier river channels, and other evidences of erosion and deposition which record a river's past behaviour.

Systematic records of flood stages on rivers in the United States do not generally extend back more than fifty or sixty years at most. Knowledge of earlier flood stages may cover, with considerable completeness for some rivers but usually without much detail, the outstanding floods since acteristics of a river in respect to the magnitude and frequency of lesser floods, but such records are entirely inadequate for disclosing the expectancy of the rare floods of great magnitude.

In March 1936, floods occurred in the northeastern part of the United States which caused crests on many rivers that were higher by several feet than had been recorded since the settlement of the country. Similarly, the more recent extraordinary floods of January and February 1937 in the Ohio and mid-Mississippi Valleys were greater than any known since the time of white settlement. Stages higher than previously recorded occurred on the Ohio River from Point Pleasant, W. Va., to its mouth at Cairo, Ill., a distance of about 700 miles, and on the Mississippi River from the mouth of the Ohio to a point below Helena, Ark., a distance of more than 300 miles. The excess of the flood crests above the highest previous records was greatest in the vicinity of Louisville, $\mathrm{Ky}$., where all previous stages were exceeded by 10-11 feet. At Cincinnati, Ohio, the flood crest was 8.9 feet higher than had occurred in eighty years of continuous record and 4 feet higher than the highest previously known stage, which is reported to have occurred in 1773 . With rare exceptions, the protective levee systems were overtopped and great damage to property and considerable loss of life were caused in cities, towns, industrial establishments and transportation routes that occupied the flood plain. 
Fig. 1 shows by bars in chronological order the maximum yearly stages of the Ohio River at Cincinnati, Ohio, continuously for the eighty years, 1858-1937, inclusive, and for certain major floods prior to that period.

Fig. 2 shows, as explained thereon, the maximum yearly stages at this place for the eighty years above specified, arranged in order of magnitude and plotted upon arithmetic-probability paper. The graduations on this paper have the characteristics that if a series follows the laws of normal probability the plotted points will define a straight line. This type of graduation is used because it seems to show the observed data effectively.

In so far as Fig. 2 illustrates the magnitudefrequency characteristics of the Ohio River in the production of floods at Cincinnati, the river does not seem to have departed far from its demonstrated character in producing the excessive stage of 1937 . However, on the basis of the records prior to 1937 , it is probable that the deduction would have been warranted that such a stage as occurred in 1937 would be of such rare occurrence as to justify little consideration with respect to protective works or occupancy of the flood plains. In the popular mind a flood of such magnitude was considered essentially impossible.

The series of rains which caused these recordhreaking Ohio-Mississippi floods began toward the end of December 1936, continued through most of January and were unusually excessive in the latter month. The associated weather conditions resulted from abnormal movements and interactions of air masses over a large region. The distribution of barometric pressure "resulted in a continuous northward and north-eastward movement of tropical air masses over the area roughly from Louisiana and Tennessee eastward to the Atlantic States, New England and New York, while air masses of polar origin moved southward almost continuously over much of the western half of the United States. . . .

"The extremely heavy rainfall over the Ohio Valley, Tennessee and Arkansas and part of the adjoining areas was in general caused by the fact that this area was so located with relation to the very deep areas of high pressure on either side that at the earth's surface the line of contact between the warm, moist air from the south, and the dense, cold air of polar origin that came in over the Ohio and middle Mississippi Valleys on many days from the north and north-east, lay somewhere over this area much of the time; and the less dense warm air from the south (or south-west) was forced to rise over the cold and denser air. The rapid lifting of the very moist air of tropical origin resulted in abundant precipitation."*

The total rainfall for the month of January

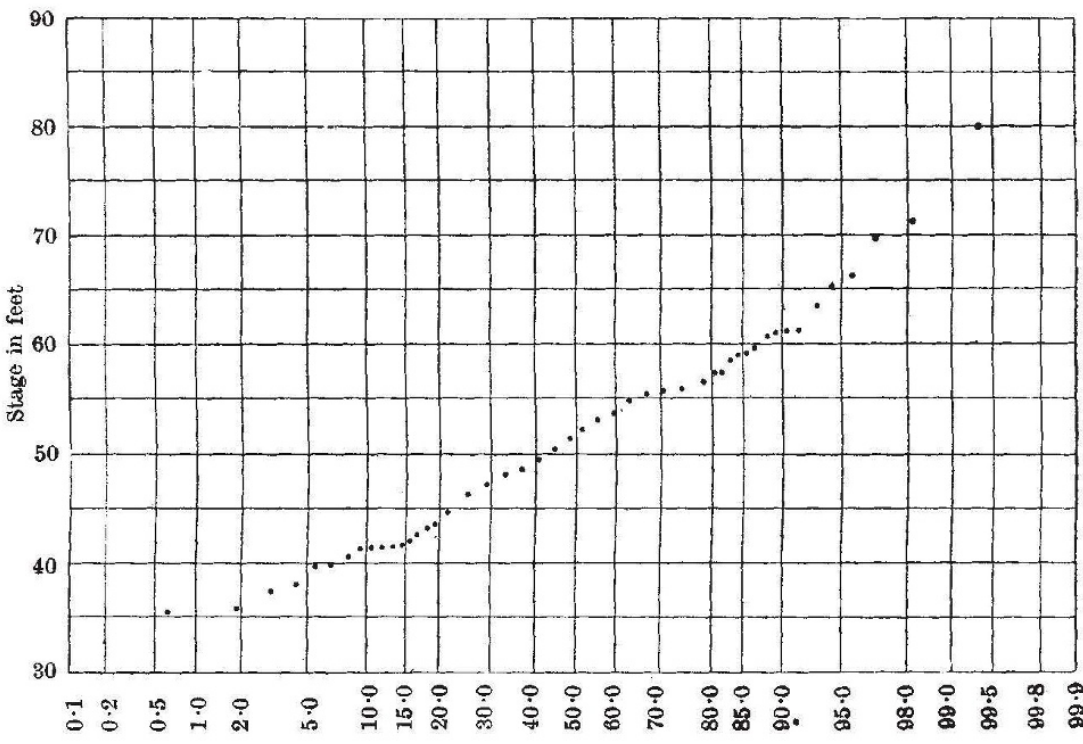

Fig. 2.

Maximum anndal flood stagm, OHio River, Ctincinnati, Onto, 1858-1937. RECORDS PLOTTED IN ORDER OF MAGNTTUDE ON ARITHMETIC PROBABILITY PAPER. FOR THE MID-48 YEARS, THE PLOTTED POINTS CORRESPOND O THE MEANS OF SUCCESSIVE GROUPS OF THREF YEARS IN ORDER TO AVOID CONFUSION CAUSED BY A MULTIPLICITY OF PLOTTED POINTS. was four times the normal, or more, over approximately 35,000 square miles. The area of heaviest precipitation included the middle and lower Ohio River valley, mainly along the Ohio River and the lower valleys of its tributaries (Fig. 3). The rainfall occurred not so much in a progression of general storms through the region as in a progression of somewhat sporadic storms marked by considerable variation in local distribution, and moving in a general north and north-east direction. The average rainfall in January over the drainage basin $(203,000$ square miles) of the Ohio was slightly more than 11 inches.

The floods occurred in a season when normally there might have been considerable snow, but, because of the prevalence of exceptionally

* Statement by C. L. Mitchell, forecaster, United States Weather Bureau, Monthly Weather Review February, 1937, p. 72. 
warm winter temperatures, the snowfall was light and had no appreciable influence on the floods.

The rains in December and early January reduced the capacity for surface storage and absorption by the ground that otherwise would have been available, and filled the channels of lower reaches of the rivers which later were sub-

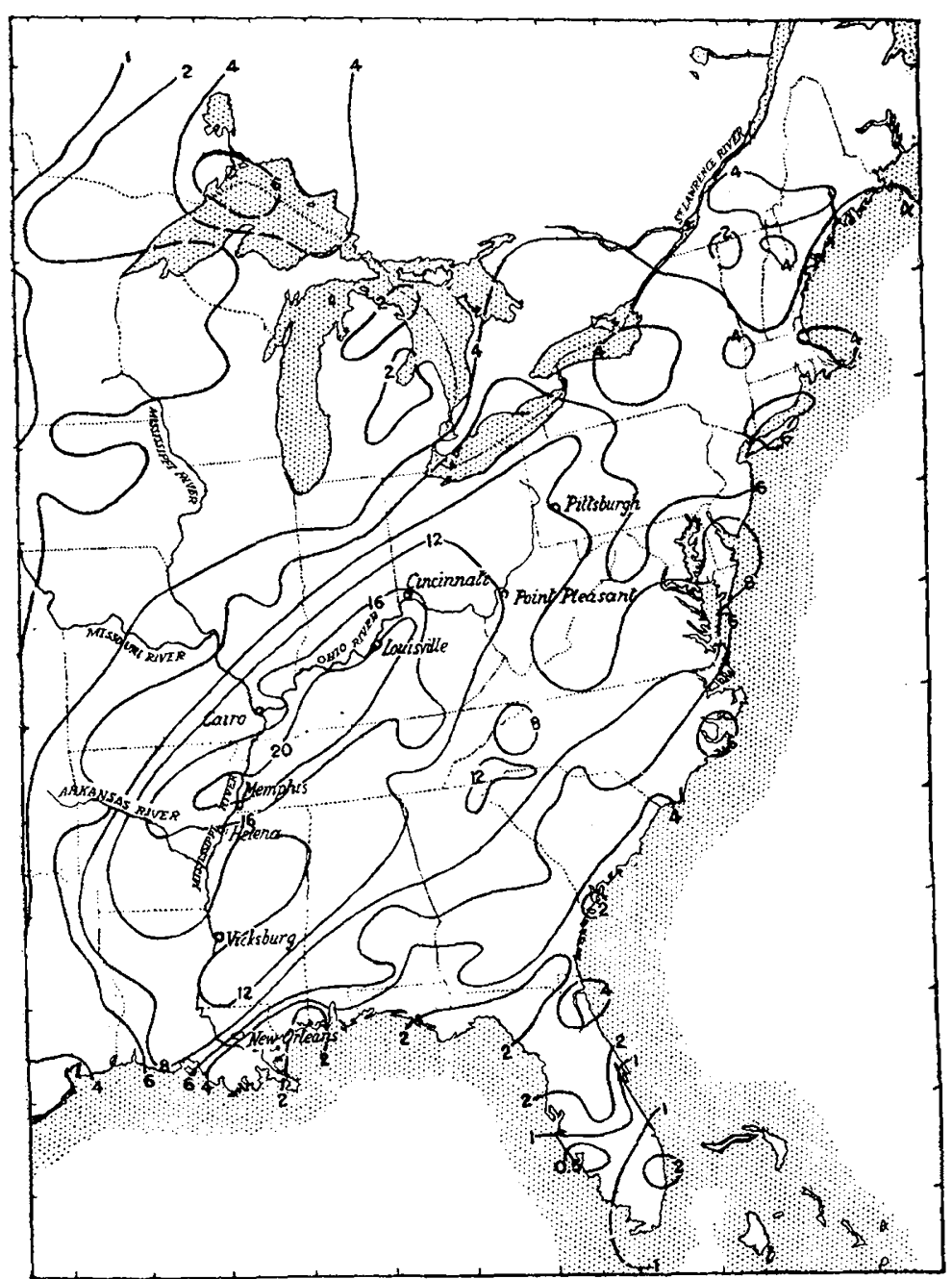

Fig. 3

Totat PRecipitation IN INChes, JANOARY 1937, FROM UNited States Weather BuREaU Monthly Weather Review, Jandary 1937.

1936 originated in the tributaries of the upper Ohio River and caused record-breaking stages at Pittsburgh, Pa., and for a distance of approximately 100 miles below that city. The peak which occurred at Pittsburgh on March 18 reached Louisville, $\mathrm{Ky}$., a distance of about 600 miles, 11 days later, on March 29. In contrast, the 1937 flood reached its crest at Pittsburgh on January 26 and at Louisville on January 27 , thus giving evidence of extreme concentrations of flood waters nearly simultaneously in several hundreds of miles of the channel of the Ohio River. The flood was at crest at the mouth of the Ohio River, a distance of 980 miles below Pittsburgh, on February 3. This crest moved down the Mississippi and reached Memphis, Tenn., a distance of 227 miles, on February 10 ; Vicksburg, Miss., a distance of 602 miles, on February 21 ; and New Orleans, a distance of 960 miles, on February 28. At Cairo, Ill., at the mouth of the Ohio, the Ohio and Mississippi were higher for a period of nineteen days, from January 24 until February 11, than any previous record. Preliminary computations indicate that the mean discharge of the Ohio River for this nineteen-day period was approximately $1,650,000$ c.f.s. from a drainage area of 203,000 square milesabout 8 c.f.s. per square mile. The maximum discharge was about $1,850,000$ c.f.s.

Topographic maps show a pronounced flood plain adjacent to the Ohio River, in the middle and lower valley. At the margin of the flood plain the reduction of spacing of the contours is so marked as to produce an effective visual impression as to the location of this margin. A definition by outline of the overflow areas of the 1937 floods indicates the apparent flood plain to have been almost

ject to the most excessive rainfall. As a result, an exceptionally large part of the heavy rainfall of January 20-25 ran into the streams. The especially heavy rainfall in the middle and lower Ohio Valleys was essentially superimposed upon full rivers resulting from the preceding days of rain in the upper parts of the basin.

The peculiarities of the floods of 1937 may be illustrated by a comparison with the floods of March 1936 in relation to the progression of flood crests down the Ohio River. The floods of March wholly occupied from the vicinity of Cincinnati to the mouth. Above Cincinnati, as the excess above previous crests decreased, increasingly more of the flood plain appears outside the overflow area.

In order to produce the characteristic topography of this valley, the Ohio in past ages must many times have occupied the flood plain in a degree similar to that of 1937 . The evidence and experience seem to demonstrate that there is. a place in the planning of flood control works for () 1937 Nature Publishing Group 
appropriate consideration of the recurrence of the great floods which geological evidence shows have occurred many times in the past. Such consideration would serve as a corrective against failure to realize adequately that a series of rains like that which produced the 1937 floods can recur, and also would tend to produce a more sound understanding and befitting humility as to the limitations of the works of man in effectiveness against all possible floods. Nature can produce floods which it may not be practicable for man to control, and it behoves man in the municipal and industrial development of river valleys not to overlook the need for meeting those events that are associated with flood catastrophes which it is not practicable for him to prevent.

\title{
Modern Study of Plants in Relation to Education*
}

\author{
By Prof. E. J. Salisbury, F.R.S.
}

$\mathrm{I}^{\mathrm{F}}$ we cast our minds back on the general attitude adopted towards botany in the latter part of the eighteenth century, we cannot but be struck by the almost apologetic phraseology of its votaries and the curious grounds upon which they rationalized its pursuit. Rousseau, for example, described botany as a study of pure curiosity that has no other real use than that which a thinking, sensible being may deduce from the observation of Nature and the wonders of the universe. I venture to think that many otherwise educated people to-day would express similar sentiments, though in more modern and probably less complimentary language.

The teaching of our subject has been in no small degree to blame for the widespread misconceptions as to its aims and content. For long regarded as a harmless and elegant occupation for the female sex, botany only survived as a study of practical utility because of the continued necessity for medical practitioners to acquire some knowledge of materia medica. How perfunctory was much of this teaching is indicated in that charming book, "Leaves from the Life of a Country Doctor", where the late C. B. Gunn describes how as a medical student in 1878 "the botany class gave me a 'scunner' at the subject which has lasted ever since".

The old technological significance for medicine has long since gone, but a newer and vastly more important significance remains, both cultural and vocational, which has rarely been stated, let alone stressed. Despite the vastly enlarged content of botanical knowledge since those days, the general conception of botany has remained much what it was then. The high value of botany as an educational subject and indeed its absolute necessity in any system of real cultural development are aspects which botanists have failed to present and emphasize.

* From the presidential address to Section K (Botany) of the British Association, delivered at Nottingham on September 2.
The protagonists of compulsory Greek and Latin of the last century valued very highly, and rightly so, the cultural content which a study of the humanities could provide. It is easy for us to be wise after the event, but now that the dust of that controversy has cleared away we can see that failure to apprehend that there are other approaches to the same mental salvation led to an unfortunate insistence upon the means rather than upon the end.

But whilst scientific workers justly claim that cultural value is the monopoly of no one subject and that those brought up in the classical tradition may be as much philistines as any man of science, it is undoubtedly true that the immense cultural potentialities of scientific thought have too often been neglected for the sake of mere erudition. There is a general tendency for university teaching to become more and more vocational as the specialized demands of occupations become increasingly exacting. Thus, not only do technological aspects grow more obtrusive, especially in the final courses of certain subjects, but also there is a trend, in the direction of this change, making its influence felt, further and further back in the student's training, so that we find, for example, certain sections of the medical profession demanding that the preliminary education should have a more direct bearing on the future occupation of the student, despite the fact that this can only be accomplished at the expense of their general education and culture. With the long course of training which most professions to-day require and the financial strain that this often involves upon parents, one cannot but sympathize in the wish to provide some relief, but if this is to be accomplished without detriment to the ultimate standing of the professions themselves, it can only be by an increased concentration on the more general aspects of culture in the schools. So far as biology 